\title{
ANTI-RHEUMATIC DRUG INDUCED MANIC EPISODE IN A CASE OF PRIMARY SJOGREN'S SYNDROME
}

\section{Authors:}

Dr. Sagar Garag\#1, Dr. Sameer Belvi Mangalwedhe ${ }^{2}$ \#Presenting author, 1- Junior Resident Psychiatry, 2-Assistant professor, Karnataka Institute of Medical Sciences, Hubballi

Introduction: Sjögren's syndrome (SS) is a common autoimmune diseases with a prevalence $2 \%$ to $4 \%$ [1]. It is characterised by a chronic inflammation of the lacrymal and salivary glands, which leads to exocrine hypofunction and the well recognised clinical features of xerophthalmia and xerostomia. Psychiatric presentation of primary SS also suggests that mental disorders can occur as 1) Primary presentation 2) Response to a psychological distress or a reaction to a chronic rheumatological disease. [2]

Aims: To report a rare case of antirheumatic drug induced Manic Episode in a case of Primary Sjogren's Syndrome.

Methodology: Ms M a 21 year old unmarried female student was diagnosed as Primary Sjogren's syndrome by a rheumatologist. Treated with Tab. Prednisolone 40 mg/day. Prednisolone and Methylcellulose eye drops. In the following 2 weeks patient developed behavioural changes characterized by elevated mood, voluminous and over-inclusive speech, increased religiosity, hypersexuality, loud singing, increased energy levels and decreased need for sleep. No h/o substance use. No $\mathrm{P} / \mathrm{H} / \mathrm{O}$ psychiatric illness. Family history of suicide in elder sister. Complete blood cell counts, thyroid studies and Imaging were all within normal limits. ANA was positive for SS-A and Ro-52. A provisional diagnosis of Prednisolone induced manic episode according to DSM-5 was considered. Severity was assessed by Young Mania Rating scale(YMRS)[3].
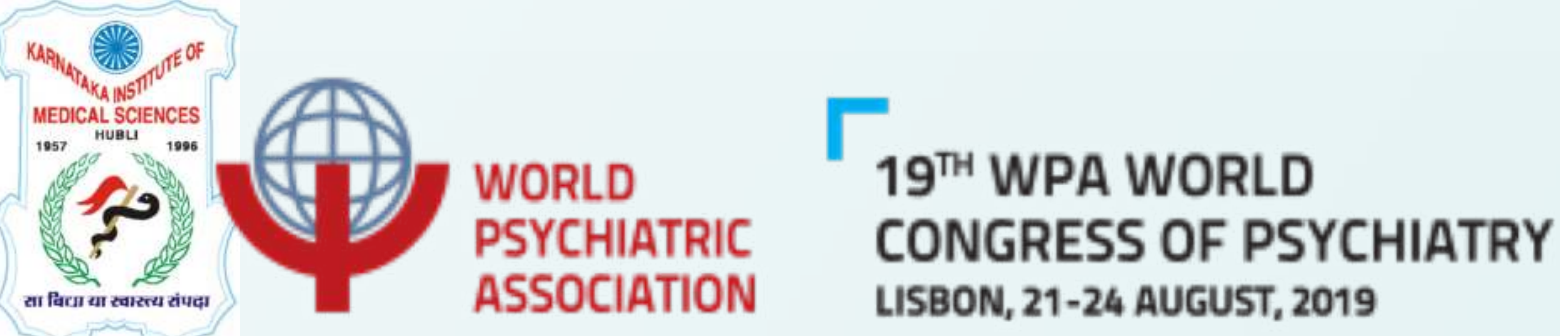

A provisional diagnosis of Prednisolone induced manic episode according to DSM-5 was considered. Severity was assessed by Young Mania Rating scale(YMRS)[3].

YMRS score was 30. A score of 7 on Naranjo Adverse Drug Reaction Probability Scale showed 'probable' association of antirheumatic drug and manic episode.[4] ADR can be classified as "Probable" according to WHOUMC causality categories.[6]

Results: Tablet Olanzapine $10 \mathrm{mg} /$ day was initiated and dose escalated to $15 \mathrm{mg} /$ day. Prednisolone was tapered and stopped. Hydroxychloroquine $200 \mathrm{mg}$ /day was initiated. Patient achieved remission in 4 weeks measured by YMRS score of 4 .

Discussion: The causality assessment system proposed by the World Health Organization Collaborating Centre for International Drug Monitoring, the Uppsala Monitoring Centre (WHO-UMC), and the Naranjo Probability Scale are the generally accepted and most widely used methods for causality assessment in clinical practice. Psychiatric presentation of primary SS could also be an adverse effect of antirheumatic drug.

Conclusion: This case focuses attention on the possibility of anti-rheumatic medication inducing a manic episode. Caregivers and patient should be cautioned to observe for early signs of manic episode after initiation of anti-rheumatic therapy. Better adapted prescription of anti-rheumatic agents and appropriate psychotropic therapy, can lead to remarkably rapid remission.

\section{References:}

1. Patel, Ruchika and Anupama Shahane. "The epidemiology of Sjögren's syndrome” Clinical epidemiology vol. 6 247-55. 30 Jul. 2014, doi:10.2147/CLEP.S47399

2. Pelizza et al.: Psychiatric disorder as clinical presentation of primary Sjögren's syndrome: two case reports. Annals of General Psychiatry 2010 9:12.

4. Young RC, Biggs JT, Ziegler VE, Meyer DA. A rating scale for mania: reliability, validity and sensitivity. Br J Psychiatry. 1978;133:429-435.

5. Naranjo CA et al. A method for estimating the probability of adverse drug reactions. Clin Pharmacol Ther 1981; $30: 239-45$.

6. The use of the WHO-UMC system for standardised case causality assessment. Accessed from: https://www.who.int/medicines/areas/quality_safety/safety_efficacy/WHOcausality_assessment.pdf 